\title{
The Nexus between Corporate Relations and Employee Relations: A Conceptual Review
}

\author{
Ben Odeba, Misal, Daburi Bello and Katu, Hilda Nankyer \\ Department of Mass Communication, Nasarawa State University, Keffi, Nigeria
}

\begin{abstract}
The purpose of this analytical review is to discover that the field of public relations is much more sophisticated now than it used to be due to both internal and external changes. Anchored on the Relational Dialectics Theory and RACE Model of Public Relations, this study reviewed the concepts of corporate relations and employee relations as well as the relationship which exists between them. The study adopts descriptive research design. The review shows that no organization exists in isolation; there is need to relate with the various publics particularly the employees and that corporate communication is a vital tool for creating and sustaining corporate and employee relations. The review further indicates that the connection between corporate relations and employee relations is both complex and essential. The review validates the view that there can be no lasting good corporate image or corporate communication and relationships with external publics without a cordial and mutually beneficial relationship with the employees (internal publics). The review clearly shows that happy employees are productive employees and that successful businesses or organizations are the ones which know how to manage relationships with their employees in order to build lasting employee satisfaction, productivity and a vibrant corporate reputation.
\end{abstract}

Key words: Corporate relations, employee relations, Nexus, corporate communication.

\section{INTRODUCTION}

$\mathrm{E}$ mployee relations refers to the policies and practices which are concerned with the management and regulation of relationships between an organization, the individual staff member, and groups of staff within working environment. Corporate relations on the other hand is any potentially sustainable relationship between an organization and other organisations and or the community and the employees. Corporate relations facilitate mutually beneficial relationships with companies to achieve business objective through research, recruiting, or employee development (Ngari and Agusioma, 2016). These are the two sides of the same coin; an organization relating with itself within the context of work environment and at the same time relating with others outside the organization. This relationship, just like any other kind of relationship is created and sustained through effective communication skills, social media savvy and relationship building. In the twenty first century, social media savvy is not optional in creating and sustaining relationships be it among corporate organizations or among individuals.

The field of public relations has become much more sophisticated now than it used to be due to both internal and external changes. The internal changes have to do with marketing, strategy, as well as operations which the corporate communications officer and his staff need to be aware of in order to implement the programme, and most importantly the need for the corporate communication officer to have the ears of the Chief Executive Officer (CEO)in order to be really effective. The external changes have to do with digital technology that affects all elements of corporate communication and multiplicity of stakeholders.

Studies have revealed that employee relations and corporate relations are subsets of public relations. It is also noteworthy that no organization can survive in isolation and that communication is the bed-rock of every successful public relations. Therefore, by extension, communication is the engine-room which drives effective and efficient corporate relations as well as employee relations in an organization. Successful relationships, be it at personal level or corporate level is essentially a product of combined efforts of both parties involved.

Scholars have argued that an organization cannot consistently improve interdependent systems and processes until such an organization progressively perfects "interdependent and interpersonal relationships". It is the quality of the employee's workplace relationship that in most cases impacts on the level of employee's motivation and subsequent performance. How well they engage with the organization, especially with their immediate environment which in most cases are their colleagues, influences to a great extent their error rate, level of innovation and collaboration with other employees, absenteeism and, ultimately, how long they stay in the job (rate of labour turnover). Harmonious relationship between each organisation (employer) and its employees are essential to that endeavour. Corporate relations between each employer and its employees may assure that the responsibilities and authorities granted to and by statute are carried out in an atmosphere which permits the fullest participation by employees in the determination of conditions of employment which affect them (Ngari and Agusioma, 2016).

From the introduction, which gives the background to this study, it has been established that employee relations is one of the vital determinants of work place performance. In addition, studies have shown that many organizations do not give employee relations the needed priority attention it deserves. This vital aspect of organizational image building and success being neglected forms the basis for this review. Another aspect of concern in this study is the interconnectedness or the 
nexus between employee relations and corporate relations. Studies have revealed that many organizations rush to project their corporate image without properly and adequately establish a cordial relationship with their most important publics - their employees. It is in view of the foregoing that this study is undertaken to review, explain and clarify the connection between corporate relations and employee relations and the benefits of a successful employer-employee relations to both the organization and the employees.

The main objective of this study is to review the connection between employee relations and corporate relations, as it affects the corporate image or reputation of an organization. The specific objectives of the study are to examine the effects of corporate relations and employee relations; disputes resolution, employment practices and employee/corporate communication on organization performance. Every reasonable and purposeful institution or organization in the modern world will always be concerned with its performance and its corporate image. Performance management has been defined as a strategic and integrated approach to delivering sustained success to organizations by improving the performance of the people who work in them and developing the capabilities of teams and individual contributors (Armstrong and Baron, 1998 cited in Ngari and Agusioma, 2013). Though various factors do affect this main objective of any organization's overall performance, employee relations emerge to be a major factor influencing organization's corporate relations or image as well as performance. This study, therefore, reviews this very important aspect of organization's corporate relations or image, explains the connection between corporate relations and employee relations, and recommend the way out of the fallouts.

\section{THEORETICAL FRAMEWORK}

This study is anchored on the Relational Dialectics Theory and RACE model of public relations. The acronym "RACE" stands for Research, Action, Communication and Evaluation. According to Otuekere-Ubani (1997, p. 62), the RACE model of public relations sees a public relations practitioner as not just a listener and counsellor, but also a "communicator" and an "evaluator". Many times, when research is mentioned, the assumption is that the public relations research should be done only to improve on the quality of products and or services rendered by an organization. The position of this paper is that such assumption is wrong. Research should also be done to find out or evaluate the perception of the employees about the activities of the organisation, communicate and take the necessary action. What is the perception of the employees about the relationship that exists between the organisation and its employees? Are there issues of non-payment of salaries and other benefits as at and when due? How are such issues and the likes handled? If there are, how are such issues communicated to the staff members? The best ambassadors of any organization are the employees of such organization. No employee can be a true ambassador the organization expects him or her to be if the relationship is not cordial in terms of meeting obligations, job security, constant and effective flow of information or communication (OtuekereUbani, 1997).

Propounded by Leslie Baxter and Barbara Montgomery in 1988, the major assumption of Relational Dialectics Theory is that the closer individuals become to one another, "the more likely conflict will arise to pull them apart". The proponents of this theory further state that there are no scientific laws that neatly order the experiences of friends and lovers (relationship). Hence, Griffin (2000) as cited in Asemah, Nwammuo and Nkwam-Uwaoma (2017, 194), notes that "people struggle to respond to conflicting pulls or things they feel within their relationships". In other words, the forces that strain romantic relationships are also at work among close friends, family members as well as employer-employee relationships. The view of these scholars is that communication parties experience internal conflicting pulls, causing relationships to be in constant state of flux, which is known as dialectical tension. Deductively, therefore, the Relational Dialectics Theory introduces the concept that the closer individuals become to one another, the more conflict will arise to pull them apart (Asemah, Nwammuo and Nkwam-Uwaoma, 2017). This implies that in employee relations, there is bound to be conflict and therefore, arises also the need to plan to prevent such from happening and a plan to resolve such conflict when it arises. This implies that communication is central to organising and negotiating relational contradictions.

From the perspective of Relational Dialectics Theory, Public Relations practitioners give life to an organization through their communicative skills and practices (Militaryveterangamer, 2012 cited in Nwammuo and NkwamUwaoma, 2017, p. 198). The Relational Dialectics Theory and RACE model of public relations are relevant to this study because both the theory and the model of public relations are concerned with all forms of public relations and advertising communication that concern relationship building and maintenance.

\section{METHODOLOGY}

The study adopts descriptive research design. Descriptive research design is chosen because the study is not confined to collection and description of data of any organisation in particular, rather, it seeks to review the existence of corporate relationships and the complicated series of connection between the employer and employee relationships. The descriptive design as applies in this study is used to obtain and describe the existing information on the connection between corporate relations and employee relations in organizations generally. Studies have shown that the kind of relationship that exists between corporate organisations, firms or institutions and their employees determines to a very large extent the level of employee and organizational performance. Some scholars are of the view that an effective employee relations program starts with a clearly written policy or blueprint. Usually, the policies include organization's 
philosophy, rules, and procedures for addressing employee related matters and resolving problems in the workplace. In addition, studies indicate that organisations have one form of employee relations representatives or the other that ensure that the organization's policies are followed fairly and consistently and also resolve problems or conflicts whenever they arise.

Studies further confirm that employee relations programme is not a one-size-fit-all solution. In other words, strategies for good employee relations can take many forms and they vary from one organisation to another because of the type of industry, location, size of the organisation and the individual leadership philosophies. However, the common consensus among many scholars is that all good employee relations share some elements in common. According to this school of thought, the most important and the most common elements for a successful relationship with employee is communication. The communication should not be a one-way street kind of communication. Staff members should be actively engaged in the open lines of communication. Staff members should be informed of the management plans and how those plans may affect their jobs. Withholding information from staff members most of the times, results into mistrust of leadership and damage employee morale. Staff members can be informed of the latest development in the organization via email, announcements, newsletters, employee portals, regular meetings, social media platforms, special events, and a host of others. Studies also show that effective and successful communication should go both ways; employees should be made to feel free to share their opinions, feelings and concerns. Not only that, they should also be made to understand that their opinions, ideas and concerns for the organization count Otuekere-Ubani (1997, p. 155). In other words, in the digital communication era, a platform that is user-generate-content (UGC) friendly should be adopted to create room for feedback.

\section{CLARIFICATION OF CONCEPTS}

\section{What is Employee Relations?}

Employee relation can be described as the policies and practices which are concerned with the management and regulation of relationships between an organisation, the individual staff member, and groups of staff within the working environment (University of Cape Town, 2018). According to Otuekere-Ubani (1997, p. 155), employee relations is part of an organization's public relations plan which aims at creating mutual understanding and support between management and employees leading to efficient and effective operation of the organization. In other words, employee relations need a serious plan and attention because it is the basis of production. The bedrock of employee relations is employee communication. Otuekere-Ubani (1997, p. 155) states employee communication is a very difficult task because employee public is not homogenous. That is, the employees are varied as they include management employees, supervisory employees, clerical employees, casual workers, professional employees, older employees and the younger and more mobile employees. Studies have revealed that employee communication is quite difficult and complicated, this is because so many groups exist in every company or organization due to differences in attitude, beliefs, expectations and within some groups can exist other groups.

\section{Reasons for Employee Relations}

1. Company Policy, Management Style and Performance

Generally, a policy is a definite clear course or method of action selected by individuals, groups, companies, governments, or institutions to guide and determine both the present and future decisions. Going by this definition of policy, a company policy is, therefore, definite clear course or method of action put in place by a company to guide and determine both the present and future decisions by the company. The method of actions is usually taken from among alternatives in the light of given conditions and environment. Depending on the given circumstances, policy can be proactive. A reactive policy is one which is created in response to a current pressing situation while a proactive policy is one which is created or designed to avert a problem. In other words, reactive policies are meant to take care of prevailing situation or circumstances while proactive policies are also meant to prevent a problem from occurring. For instance, when the COVID-19 pandemic broke out in 2019, governments and institutions all over the world including corporate organizations such as the WHO had to create reactive policy such as the COVID-19 protocols which are being observed globally in order to curb the spread of the deadly virus.

(Otuekere-Ubani, 1997), (WHO, 2020).

Management style is the method used by managers to plan, systematize, and arrange work effort to achieve the goals of a company. It also includes how authority is utilized by those in positions of authority and how the workers or people respond or react to the use of authority to achieve the company's goals. Management style is influenced by two (2) main factors which are internal and external factors. Internal factors include management framework, encouragement, degree or level of staff skills, corporate culture, rules and priorities. External factors on the other hand are those outside the organizations that determine or influence management style such as competitors, law, consumers, economy, suppliers among others. (Otuekere-Ubani, 1997)

\section{Employees Need to be Informed}

Information dissemination is an integral part of the company management. There is a popular saying that an uninformed person is a deformed person. 
Therefore, employees need to be properly and adequately informed about the policies and programmes so that they will be in a better position to perform well in their job schedule. There can be no employee relations without providing adequate information to the employee about the policies, management style and the other activities of the organization or company. When employees are well informed about the programmes of the organization, they tend to perform better and a cordial employee relation is maintained. (Otuekere-Ubani, 1997)

\section{The Need for Employee Safety at Work}

Safety at work is a very important part of employee relations. In order for the employee to put in his best and relate well with the company or organization, there is need to ensure the security and safety of the employee while at work. Employee safety refers to the general security atmosphere in a work place. The assurance that employee is safe at his place of work makes room for better employee relations and corporate relations. The assurance that employees are safe at their work environment helps them to relate well with the management and their colleagues which brings about a heathier employer-employee relations (internal publics) and subsequently improves performance. Employees who do not feel secured at their place of work cannot relate with anyone, let alone the whole organization which is responsible for providing security for the staff. (Otuekere-Ubani, 1997).

\section{Work Continuity/Feedback Processes}

Relationship is a give and take situation that helps for work continuity and positive feedback from the individual employee, groups of workers in different units and departments of the organization. Therefore, work continuity and feedback process hinge on how conducive the atmosphere is for work to continue and for management to feedback from the employees. (Otuekere-Ubani, 1997)

\section{Explaining New Developments}

In every organization, new developments are bound to occur. For there to be a cordial corporate relations and employee relations, employees should be constantly kept up to date with the new developments in such an organization. Some new developments, especially in the digital age, are so complex that some form of explanation is necessary, perhaps because of the technicalities involved. The organization should endeavour to employ the service of a technical person to explain the new developments to the employees. This will go a long way to boost the kind of relationship that exists between employer and employees.

\section{International Relations}

Nations and corporate organizations relate with one another across borders. The ability and capacity to relate well across borders depends to a large extent on how well an organization relates with its employees. Many scholars have defined international relations in diverse ways. However, for the purpose of this study, the one given by the encyclopaedia Britannica is used. Going by that definition, international relations is the study of the relations of states with each other and with international organizations. In other words, nations relate with corporate organizations such as bureaucracies, political parties and interest groups just as they relate with one another. It is noteworthy that international relations is also an academic discipline such as political science, mass communication, economics, sociology and so on. Relationship at this level can only be achieved when the existing nexus between corporate relations and employee relations is sound and cordial.

\section{Good Industrial Relations}

This is slightly related to corporate relationship with organizations across borders. One of the external publics of the corporate organization the one that exists between a corporate organization and the labour unions and the likes. This is a very important external public of an organization. Maintaining a cordial relation with employee is paramount to relating well with other industries and labour unions. This helps to sustain a healthy employee relation and corporate relations.

\section{New Worker Induction}

Induction is an integral part of employee relations and corporate relations. New employees or workers in an organization need to be properly informed or educated about the workings of the organization such as the organizational culture and operations. This is achieved through induction when new workers or employees are engaged in an organization. Different organizations may design their induction programmes as they dim fit or as it suits their work space, culture and trends. The over all aim is to maintain a cordial employee relations and corporate relations in an organization. (Otuekere-Ubani, 1997).

\section{Benefits of successful Employee Relations}

Studies have confirmed that maintaining a cordial employee relation in an organization has amazing benefits to both employer and the employees. According to Otuekere-Ubani (1997, p. 155), the benefits or advantages of employee relations are, but not limited to the following: 
a) Reduced rate of lateness and Absenteeism

Cordial employee relations reduce the incidences of lateness and absenteeism as workers are happy with their work and the work environment is friendly for them to stay.

b) Increased productivity

Good or cordial employee relations brings about increased productivity. Happy workers are productive workers.

c) Low labour turnover

In an organization or company where cordial employee relations subsists, employees have a strong sense of belonging, therefore, they will not leave such a company thereby reducing labour turnover.

d) Low industrial conflict

Cordial or mutually beneficial relationship minimizes industrial conflict which eventually brings about industrial harmony.

e) Overall Company/Organization Growth

Good employee relations help to speed up organizational growth. This is because everyone works with one mind towards the growth of the organization.

f) Reduced cost and increased productivity

Cordial relationship encourages sincerity and honest behaviour among the employees and incidentally cordial corporate relations. When every member of the corporate organization works with high sense of belonging, they are bound to be honest in their dealings, thereby reduce the cost of production and increase productivity. (Otuekere-Ubani, 1997)

\section{What is corporate relations?}

Corporate relations is any potentially sustainable relationship between an organization and other organisations, the host community and the employees. Corporate relations facilitate mutually beneficial relationships with companies to achieve business objective through research, recruiting, or employee development (Ngari and Agusioma, 2016).

\section{THEORETICAL AND RELATED LITERATURE REVIEW}

As earlier stated in the methodology, this study uses theoretical review and review of related literature to examine the nexus between corporate relations and employee relations. Ngari and Agusioma (2016) did research on "The Influence of Employee Relations on Organization Performance of Private Universities in Kenya". Using the employee organization relationship theory, the findings indicate that the quality of the employee's workplace relationship impacts greatly on the level of employee's motivation and subsequent performance. The study further shows that how well the employees engage with the organization, especially with their immediate environment that are in most cases their colleagues, influences to a great extent their error rate, level of innovation and collaboration with other employees, absenteeism and, ultimately, how long they stay in the job. This implies that although the study was confined within the private universities in Nairobi Central business District, the findings are proofs that employee relation, when properly created and maintained impacts positively on the corporate image and the general organizational performance. In addition, findings reveal that middle and lower levels of management are in a position to give reliable information on influence of employee relations on organization performance. The study also found that industrial relations, employment practices and employee communication affect organization performance. The study concluded that, HR (Human Resources) department is a key department of any high-profile institution or organizations and that organizations need to involve their staff in decision making.

\section{Theoretical Review}

Scholars have developed several theories which are applied in the study of employee relations and corporate relations. For the purpose and scope of this study, a few of them are reviewed.

\section{Stakeholder Theory}

First appeared in an internal memorandum at the Stanford Research Institute in 1963, stakeholder theory deals with organizational management and business ethics that accounts for multiple constituencies impacted by business entities like employees, suppliers, local communities, creditors and others. The main argument of this theory is that the firm or organisation should create value for all stakeholders, not just shareholders. Stakeholder theory is a view of capitalism which stresses the interconnected relationship between an organization and its publics (internal and external) which includes employees and others. Stakeholder theory was posited in the $20^{\text {th }}$ century by an economist called Milton Friedman.

The idea is that a company's stakeholders include just about anyone affected by the company and its workings. This is the crux of this study. The theory is used to anchor this study because it relates to the core aim of this research which has to do with how a company relates with both its internal and external publics in order to achieve its set goals. Milton Friedman's further assumption holds that a company needs "those groups without whose support the organization would cease to exists. This is inline with the position of this paper which draws the conclusion that no organization can exist or survive in isolation. The company needs the support of all its stakeholders to more move ahead and achieve its goals and objectives. The stakeholder theory covers a very wide areas of study, however, for the scope of this study, only two assumptions are reviewed. (Otuekere-Ubani, 1997).

\section{Human Relations Theory}

This theory belongs to the human relations school. The human relations theory holds that workers are regarded as qualitatively different from other resources used in production. Therefore, it is assumed that if workers are denied 
autonomy on the job and or are reduced to acting as mere extensions of the machinery they operate or are given work that inhibits their capacity to create and think, it is argued that they will invariably find ways to subvert the methods of control that enforce these conditions. This implies that the principal task of management in this regard is to employ workplace relations in ways that enable employees to feel personal satisfaction with being involved with the organization. In other words, companies operating on this basis are expected to recognize the right of employees to have a say in how they are governed (Judge, 2002). Hence, consistent flow of communication or information between an organization and its employees is a very important aspect of employee relations. The perspective shows that this is lacking in many organizations.

In addition, it is expected that the organization should take an active interest in developing the skills of employees as a means of demonstrating a commitment to their personal development and well-being. The aim of this managerial approach to employee relations is to seek to reduce internal tensions by developing the sense of workplace satisfaction for employees through techniques that involve them in the organization and regulation of work (Cropanzano \& Mitchell, 2005). This infers that workplace satisfaction through employee relations reduces tensions among workers and between employees and the organization. Be that as it may, many organizations either do not have a public relations unit or such units are both poorly manned and inadequately equipped with modern communication skills and technology. Therefore, there is the need to create and maintain a vibrant public relations unit or what is known now in many organizations as Public Affairs Directorate.

\section{Scientific Management Theory}

Taylor (1974) theory of scientific management holds that the employment relations choices of management must start from the assumption that employees are immature in the ways of work and are prone to avoid it whenever possible, and have limited, self-centred aspirations and time-horizons. In other words, this conflict with the aspirations and time-horizons of organizations, efforts to reduce the outward manifestation of internal tension are to be undertaken by direct and highly rigid control of the workplace activities of employees. This implies that leadership when recruiting and directing workers, to have a clear understanding of the tasks or the job descriptions employees are expected to perform, and to have unrestrained prerogatives to control the pace and processes under which they work. The implication of this theory is that companies subscribing to this form of management practice should reduce work to its basic elements, so that the skills of workers necessary to undertake tasks are kept to a minimum. Employees should be treated impersonally and collectively, with any workplace issues being referred to management. In other words, the management approach to employee relations is one that seeks to suppress internal tension over the distribution of organisational power by ensuring that management retains superior knowledge about the structure and organisation of work, and has the authority to direct workers as it sees fit (Cropanzano \& Mitchell, 2005). The challenge from the review is that many organizations that have communication officers do not either maximize the personnel or that the management or the chief executive officer (CEO) do not give listening ear to the communication officer in order to implement or formulate organizational communication policy which addresses such issues. Disgruntled workers or employees will ultimately give low quality output.

\section{CONCLUSION}

It has been established that many organizations suffer corporate image or reputation problem not because they do not have what it takes or the resources to establish, sustain and project a positive image, or a mutually beneficial relationships with all its publics. But they failed because they failed to use the resources (effective corporate communications as a result of adequate capacity given to corporate communication officers to operate and the changes in technology), they have to get what they need.

Digital public relations is yet another challenging aspect of public relations practice in the $21^{\text {st }}$ century. Particularly, during the covid-19 pandemic global lockdown, the only means of interaction with the publics of an organization is the use of digital or new media technology. No relationship can exist without communication, therefore, there is need for companies especially in the $21^{\text {st }}$ century and the incidences of covid-19 third wave, companies should do all within their power and available resources to be digitally visible and relevant in business.

The field of public relations is much more sophisticated now than it used to be due to both internal and external changes. The internal changes have to do with marketing, strategy, as well as operations which the corporate communications officer and his staff need to be aware of in order to implement the programme, and most importantly the need for the corporate communication officer to have the ears of the Chief Executive Officer (CEO)in order to be really effective. The external changes have to do with digital technology that affects all elements of corporate communication and multiplicity of stakeholders.

\section{RECOMMENDATIONS}

In view of the benefits of successful employer-employee relations, this paper recommends among others that organizations should establish and maintain a sound cordial relationship with its employees through effective corporate communication, before they project their image or reputation out there, because the employees are the real ambassadors and the true image makers and reputation projectors for the organization. 
Based on the scope of this study, the researchers recommend further research into this topic based on the current trends in the filed of public relations in the digital age.

\section{REFERENCES}

[1] Asemah, E., Nwammuo, A. and Nkwam-Uwaoma, A. (2017) Theories and Models of Communication. Revised Edition. Jos: Matkol Press.

[2] Cropanzano, R. and Mitchell, M. S. (2005). Social Exchange Theory: An Interdisciplinary Review. Journal of Management 31(6). 874 - 900. DOI: $10.1177 / 0149206305279602$
[3] Judge, T. Locke, (2000). Job satisfaction: Research and Practice. London: Dp publication. 16.

[4] Judge,T, \& Illies, R. (2002), Relationship of personality to performance motivation. Journal of applied psychology Butterworth, Heinemann: New Delhi.

[5] Ngari, J. and Agusioma, N. (2016). Influence of Employee Relations on Organization Performance of Private Universities in Kenya. International Journal of Research and Studies. Vol. 2(8).

[6] Otuekere-Ubani, C. (1997). Modern Public Relations: Theories, Principles and Practice. Ibadan: Pelcas Print and Publishers.

[7] WHO (2020). World Health Organization Report on COVID-19. www.who.org 